\title{
CONSIDERAÇÕES SOBRE O JUIZ, A SENTENÇA E A TUTELA PREVENTIVA NA HISTÓRIA DO PROCESSO CIVIL ${ }^{1}$
}

\author{
Cesar Antonio Serbena*
}

\section{INTRODUÇÃO}

\section{A IMPORTÂNCIA CRESCENTE DA TUTELA DE URGÊNCIA}

Já são conhecidas de longa data as limitações do processo de conhecimento no Direito Processual Brasileiro e principalmente a sua insuficiência em suprir as novas demandas sociais. Por essas razões o processo cautelar e mais recentemente a tutela

* Doutor em Direito e Professor Adjunto da Universidade Federal do Paraná.

1 O presente trabalho foi apresentado originalmente à disciplina de Teoria do Direito Processual Civil Contemporâneo, ministrada pelo Prof. Dr. Luiz Guilherme Marinoni, ainda quando o autor cursava o Mestrado na Faculdade de Direito da Universidade Federal do Paraná, em 1998. À época, o Prof. Marinoni cogitou em publicá-lo. Passados os anos, retomo seu conselho, após observar que seu conteúdo, por versar sobre a história do processo civil, ainda não perdeu a atualidade. antecipada crescem em importância, pela agilidade e simplificação de procedimentos, tão procurados pelos operadores do direito, que encontram nesses processos diferenciados os meios para suprir as deficiências do processo tradicional de conhecimento.

Segundo o Prof. Luiz G. Marinoni, a tutela cautelar transformou-se em remédio de sumarização processual, em face da lentidão do procedimento ordinário e da sua incompatibilidade com a sociedade de massa. As razões desse fenômeno são: "a) o desprezo às vias de cognição sumária, ocorrido já no direito medieval; $b$ ) a conseqüente universalização do procedimento ordinário; e c) os estreitos limites postos para a execução provisória da sentença em nosso direito."

2 MARINONI, Luiz Guilherme. Efetividade do processo e tutela de urgência. Porto Alegre, Sergio Antonio Fabris Editor, 1994. p.28. 
Aliado a esse fato, a nova sociedade industrial determinou novas relações entre o público e o privado e entre os próprios entes privados. A velocidade das negociações comerciais cresceu, juntamente com a mudança da forma estática da propriedade do século passado para uma forma mais dinâmica e abstrata. Novas figuras surgiram como o meio ambiente e o consumidor. Assim, o âmbito de aplicação das medidas cautelares amplia-se constantemente: "vai desde a proteção à honra e à personalidade, da proteção à empresa industrial e aos direitos referentes a bens imateriais, contra a concorrência desleal, desde a imposição de compromissos concernentes aos preços na distribuição de produtos do mercado, à obstação de mudança anticontratual de local de trabalho, à regulação de disputas políticas ou científicas, até a condenação a pagamentos provisionais no direito alimentar ou no da reparação ao dano." 3

Nos capítulos seguintes, é feito um breve exame das razões históricas que explicam, em parte, as limitações inerentes ao processo civil, principalmente a exclusão da função jurisdicional de prevenção do ilícito. Um dos principais fatores que determinaram o perfil do juiz tal como o concebemos se deve à influência cristã no processo, quando o ato de julgar, desde a ascensão do absolutismo monárquico, passa a ser definido como uma delegação divina e do rei ao julgador, determinando a independência quase completa do juiz em relação à política. Dessa idéia é que nasce a inspiração de

3 BAUR, Fritz. Tutela jurídica mediante medidas cautelares. Porto Alegre, Sergio Antonio Fabris Editor, 1990. p.13.
Montesquieu para elaborar a sua filosofia política de separação dos poderes.

Outro importante instituto que influenciou historicamente a atividade do juiz é a motivação da sentença, pois após a Revolução Francesa a obrigatoriedade da motivação da sentença passou a ser a forma principal de controlar e limitar os poderes do julgador.

\section{A FORMAÇÃO DA FUNÇÃO DE JULGAR}

A posição defendida por Robert Jacob ${ }^{4}$ é a de que a idéia da autonomia do juiz e do seu ato de julgar em relação à política, bem como a separação de poderes, possui origem religiosa. Mais precisamente, o julgamento de Deus é uma formação cultural original que singulariza o mundo ocidental cristão e constitui um episódio maior da constituição de uma cultura jurídica européia. Este é um episódio que traz traços fundamentais sempre reconhecíveis e podem ser determinantes de nossa vida jurídica.

O julgamento de Deus, ilustrado desde o Velho Testamento, representa um modo de interação entre Deus e os homens e um modo de resolução dos litígios próprio à cristandade latina ocidental do primeiro milênio.

As mutações dos séculos XII e XIII engendram, ao mesmo tempo que o fim das ordalias, a formação irreversível, nas vilas dos Estados nascentes, dos poderes judiciários doravante capazes de impor o respeito às regras pré-constituídas destinadas a dirimir

4 JACOB, Robert. Le jugement de Dieu et la formation de la fonction de juger dans l'histoire europeenne. In Archives du Philosophie du Droit. Tomo 39. Paris, Sirey, 1995. pp.87-104. 
os conflitos. O conjunto das regras eram identificadas àquilo que chamaremos mais tarde de direito. Esses novos juízes aparecem sob uma dupla natureza: órgãos da autoridade em nome da qual eles agem sem dúvida, mas também herdeiros de um poder anteriormente atribuído a Deus. A história da função de julgar passa no Ocidente por uma transferência de Deus aos homens.

Em uma civilização dominada pela distinção do espiritual e do temporal, a função de julgar, na medida em que ela repousa sobre uma delegação de Deus a certos homens, participa sempre do espiritual. A espiritualidade do ato judiciário permite somente explicar certos traços específicos da cultura jurídica ocidental, notadamente a autonomia do judiciário da política, racionalizada na forma bem conhecida da “separação dos poderes".

No processo de apropriação pelos homens da justiça de Deus devem nascer os sistemas jurídicos racionalizados da Europa medieval. Entretanto, a razão jurídica que se decanta no final do século XII e XIII não é una, mas dupla. O sistema inglês da Common Law e o sistema francês se reconhecem, já muito cedo, nos traços estruturais que se conservam até nossos dias. De um lado, primazia dos caracteres oral e acusatório do procedimento, espírito analítico, impedimento a toda influência exógena. De outro lado, procedimento mais largamente escrito e inquisitório, gosto pela síntese, receptividade às construções do direito ensinado, romano e canônico. Nós podemos nos perguntar se a formação dos dois sistemas não têm qualquer feição à maneira diferente de onde eles se desembaraçaram da matriz original comum do julgamento de Deus objetivo.
De fato, a Inglaterra é fiel à primeira forma de transição, o júri, este deus ex machina que, substitui a intervenção divina, permitindo desmanchar a querela sem comprometer a convicção do juiz. A razão jurídica inglesa, mais diferente daquela da alta Idade Média que a continental, desenvolve-se como uma preparação à intervenção eventual do trial by jury. Ele é colocado em forma da causa, norma sucessiva de objeções que são os incidentes de procedimento, ao final do qual o litígio tende a se reduzir a uma questão de fato, suscetível de ser decidido pelo veridito. Na França, ao contrário, a prática do recurso aos juízes juramentados não desabrochou, deixando o campo livre aos tribunais de magistrados profissionais atuarem colegiadamente. Suas técnicas processuais se inspiraram no procedimento dito romano-canônico, quer dizer, o procedimento erudito aplicado no século XII pelos tribunais da Igreja. Até o século XIV, a parte dos clérigos é muito importante na jurisdição real francesa. A influência eclesiástica conduz a reforçar então, o papel do juiz no processo e, por meio da direção e apreciação dos resultados da instrução, a fazer sua convicção na mensuração da prova. A distinção entre os dois sistemas jurídicos corresponde a dois modelos de magistratura definidos pelos modelos de interação diferente com o sagrado: o primeiro, insular, que Jacob propõe chamar sacramental, porque ele repousa sobre a consagração dos jurados pela promessa no curso do procedimento; o segundo, continental ou clerical, que erige de uma vez por todas a consciência e a razão de um juiz como competente soberano do processo. 
A delegação da função de julgar, por Deus e pelo rei, tem conseqüências que ultrapassam muito a organização do teatro e dos ritos da justiça. Pois que o juiz é responsável perante o Soberano Julgador (Deus ou o Rei), ela funda necessariamente a autonomia de sua consciência em relação ao poder temporal em nome do qual ele estatue. Portanto, ela estabelece uma relativa independência do Poder Judiciário em relação ao poder político de onde ele emana. Essa idéia é muito presente no texto dos juramentos impostos ao juiz, ou aos jurados. Eles devem procurar a imparcialidade, a abdicação de suas paixões, de seus interesses, seus medos e esquecer suas fidelidades temporais. Uma forma de renúncia do mundo que situa o ato de julgar numa zona estreita do profano e impregnada de espiritualidade. A idéia de uma autonomia fundada sobre a relação com Deus pode estar na base da concepção, aceita sem controvérsia, de um Poder Judiciário muito distante da política. Somente as raízes cristãs da cultura jurídica ocidental podem explicar a distância dos juízes em relação ao poder, em nome do qual eles proferem justiça.

\section{A MOTIVAÇÃO DA SENTENÇA}

A obrigatoriedade de o juiz motivar todas as suas decisões tem um papel historicamente importante nas limitações do seu poder de julgar. Os filósofos franceses pareceram desinteressar-se quase totalmente do problema da motivação. A afirmação da obrigação de motivar a sentença para um fim de controle democrático da função jurisdicional encontra espaço na situação concreta delineada nos primeiros anos da Revolução Francesa, concentrando os poderes no Executivo em prejuízo do poder jurisdicional. De fato, a lei francesa 16, de 24 de agosto de 1790, estabeleceu ${ }^{5}$ :

Título II, art. 10:

"Os tribunais não poderão tirar diretamente ou indiretamente alguma parte do exercício do poder legislativo, nem impedir ou suspender a execução dos decretos do corpo legislativo, sancionados pelo Rei, sob pena de traição."

Art. 12:

"Eles não poderão determinar as normas, mas se dirigirão ao corpo legislativo toda vez que acharem necessário, seja para interpretar uma lei, seja para fazer uma nova."

Título V, art. 15:

“A redação dos julgamentos, tanto na apelação quanto na primeira instância, conterá quatro

5 Para a redação deste capítulo, tomamos por base MANCUSO, Fulvio. Per la storia della motivazione della sentenza nei secoli XVI-XVII (Note in margine a studi recenti con il testo de una sentenza del 1299). In: Rivista Trimestrale di Diritto e Procedura Civile. Anno XLIX, n. 1. Milano, Dott. A. Giuffrè Editore, 1995. pp.285-310. No artigo, os trechos da legislação francesa citados estão assim redigidos:

Título II, art. 10: "Les tribunaux ne pourront prendre directement ou indirectement aucune part à l'éxercise du pouvoir legislatif, ni empêcher ou suspendre l'exécution des décrets du corps legislatif, sanctionnés par le Roi, à peine de forfaiture."

Art. 12: "Ils ne pourront poit faire de règlements, mais ils s'addresseront au corps legislatif toutes les fois qu'ils croiront nécessaire, soit d'interpréter une loi, soit d'en faire une nouvelle."

Título V, art. 15: "La rédaction des jugements, tant sur l'appel qu'en première instance, contiendra quatre parties distinctes. Dans la première les noms et les qualités des parties seront énoncés. Dans le seconde les questions de fait et de droit qui constituent le procés seront posées avec precision. Dans la troisième, le résultat de faits reconnus ou constatés par l'instruction et les motifs qui auront determiné le jugement, seront exprimés. La quatrième enfin contiendra le dispositif du jugement." 
partes distintas. Na primeira os nomes e as qualidades das partes serão enunciadas. $\mathrm{Na}$ segunda as questões de fato e de direito que constituem o processo serão colocadas com precisão. Na terceira, o resultado dos fatos reconhecidos ou constatados pela instrução e os motivos que determinaram o julgamento, serão expostos. A quarta enfim conterá o dispositivo do julgamento."

Como se pode notar, a preocupação fundamental é de conter o quanto possível o poder do juiz, seguindo a idéia de Montesquieu do juiz como bouche de la loi, sendo ao mesmo tempo uma reação geral aos poderes que os mesmos haviam ganho desde o século XIV, instaurando um autoritarismo do tipo jurisdicional que tem uma de suas máximas expressões nos arrêts de réglements (suspensão da norma) do Parlamento francês. Tal reação é também o fruto da imposição de um outro poder, o do Executivo.

É claro que, se de uma parte vêm reconhecido o fundamental princípio do controle democrático da operação dos juízes, de outra não se dá plena substância à motivação, que encontra a própria identidade em um perigoso jogo de silogismo. Esta última consideração emerge fortemente da análise do stylus que as cortes francesas seguiram quase unanimemente na motivação: um estilo que ignora quase completamente a motivação no fato e enuncia apoditicamente a norma, isto é, a ratio decidendi, sobre a qual se funda o dispositivo. Pode-se afirmar que o clima ideológico iluminista constitui um fértil terreno para o problema da motivação da sentença, mas certamente não constitui o fundamento determinante da normativa de 1790. Segundo Mancuso, esta última e, em particular, o reconhecimento da função extraprocessual da motivação são mais filhas da
Revolução política. Enfim, conclui o mesmo autor, de um ponto de vista substancial, a motivação parece suportar um contragolpe argumentativo, se se confronta a lei de 1790 com a legislação e a prática do Estado italiano pré-unitário. Os motivos representaram, porque se fala sempre e somente do ponto de vista do conteúdo e não da função da motivação, com a sua fadigante prolixidade, que ainda hoje predomina no stylus curiae italiano, um nível seguramente mais garantista em relação à motivação nascida na Revolução Francesa.

No capítulo seguinte, examinaremos a evolução histórica da tutela preventiva na formação da doutrina processual italiana, segundo Cristina Rapisarda, ressaltando o aspecto da exclusão do tema da prevenção do ilícito na formação desta mesma doutrina.

\section{PERFIL HISTÓRICO DA TUTELA PREVENTIVA SEGUNDO CRISTINA RAPISARDA}

Segundo Cristina Rapisarda, ${ }^{6}$ o tema da tutela preventiva não foi tratado autonomamente pelos estudiosos do processo civil da primeira metade deste século. Isto se deve a uma razão histórica e, sobretudo, à estranheza da noção de controle jurisdicional preventivo aos fundamentos teóricos do Estado liberal e da interpretação até hoje imperante do binômio autoridadeliberdade. Sua análise sobre a tutela preventiva na formação da doutrina processual civilística

6 Todo este capítulo é uma exposição condensada do Capítulo I "La tutela preventiva nella formazione della dottrina processualcivilista", da obra de RAPISARDA, Cristina. Profili della tutela civile inibitoria. Padova, CEDAM, 1987. pp.13-76. 
concentra-se sobre a noção de jurisdição, ação e interesse de agir, como principais pontos de referência da discussão sobre tutela preventiva.

A elaboração teórica do conceito de jurisdição soava estranha na obra dos processualistas italianos do último decênio do século passado. $O$ defeito de tratativa da matéria representou a natural conseqüência da concessão privatista do processo, na qual vem atribuída uma posição de subordinação e dependência com respeito ao direito civil substancial.

Foi comum aos processualistas do final do século XVIII a adesão ideológica ao modelo institucional do Estado de direito e aos postulados do pensamento liberal pós-iluminista. A inspiração das teses do liberalismo moderado determinou a prevalência do método exegético nos estudos sobre o processo civil, determinando também a tendência a privilegiar os valores da liberdade individual em face dos poderes de intervenção estatal, numa rígida observância do princípio da divisão dos poderes.

\subsection{A Jurisdição}

Os reflexos dessa influência doutrinal sobre a elaboração teórica do conceito de jurisdição são verificáveis sob um duplo ponto de vista. Primeiro, a tendência a favorecer os espaços de liberdade individual em relação à autoridade estatal, e a prevalência da noção de direito subjetivo conduz à conceber a jurisdição como função direta da atuação do direito subjetivo privado. Mais particularmente, individuou-se o fim específico da jurisdição civil na reintegração do direito subjetivo violado. A função de prevenção do ilícito como finalidade do processo civil determinava um alargamento dos poderes de controle do Estado-juiz e uma limitação da liberdade de regulamentação autônoma das relações jurídicas privadas. A concessão da jurisdição como forma de controle repressivo foi inspirada no princípio pelo qual o processo civil deve essencialmente obter para os direitos privados a máxima garantia social com um mínimo de sacrifício de liberdade individual.

Em segundo, a adesão ao princípio da divisão de poderes constituiu um posterior obstáculo conceitual à admissibilidade do remédio jurisdicional preventivo. Se se pensa que a intervenção jurisdicional preventiva pode resultar um fenômeno de sobreposição de poderes e, mais precisamente, a substituição do poder jurisdicional sobre o poder de controle administrativo, parece óbvio que isto se põe em contraste com um endereço teórico e institucional que contrapunha explicitamente a prevenção da inobservância do direito, ou "controllo tout court", que reconduz à atividade administrativa, e a repressão da inobservância, que relegava a atividade jurisdicional à função de garantia. Tal tendência doutrinal teve encontro na distinção entre jurisdição contenciosa, como função de repressão da violação ou lesão já verificada e jurisdição voluntária, como função de prevenção de violação ou lesão futura.

\subsection{A teoria privatista da ação}

A idéia da jurisdição como função direta da tutela dos direitos subjetivos privados vai ao encontro, na doutrina processual do último decênio do século XIX, da teoria da ação civil como direito ou faculdade 
individual, objetivando a garantia de fazerem valer em juízo os direitos subjetivos.

$\mathrm{Na}$ base de tal premissa, a ação foi concebida como entidade estreitamente conexa com o direito substancial, segundo uma noção que Chiovenda definirá "mista" ou "impura". A inspiração no pensamento de Savigny conduz a negar a autonomia do direito de ação, que foi posto como faculdade jurídica intrínseca ao direito subjetivo substancial. A prevalência, no plano ontológico, do direito subjetivo substancial induz a pôr em direta relação a faculdade de agir em juízo com a violação do direito mesmo, como requisito necessário ao concreto surgimento do direito de ação. A identificação da ação com o direito substancial inferior implicava a perfeita coincidência entre o surgimento do direito de ação e a verificação do momento patológico da violação ou da lesão do direito subjetivo material, antes do qual existia somente o direito substancial, em regime de gozo pacífico.

A relação descrita entre violação do direito substancial e surgimento da ação civil foi comum também aos autores que teorizaram, em contraste à posição do parágrafo anterior, a autonomia e a independência do direito de ação do direito subjetivo material. C. Rapisarda se refere à doutrina de Manfredini, del Viti e del Mortara. Nos escritos desses autores, o requisito da violação do direito vem colocado na estrutura lógica do conceito de ação. A autonomia do direito de ação vem argumentada, sobretudo em Manfredini e em Mortara, sobre a base da consideração que não necessariamente a ação encontra fundamento em um direito e em uma lesão efetivamente existente, bem podendo, inversamente, ligar-se a uma pretensão inconsistente, sob a ótica seja do direito, seja da violação sofrida. A noção de violação do direito tende a reaparecer, no pensamento destes autores, segundo uma perspectiva conceitual mais ampla, que tinha inspiração na premissa privatista da ação civil como direito especificamente destinado à salvaguarda da esfera jurídica individual. O direito de ação foi construído teoricamente como poder jurídico direto a estimular a intervenção jurisdicional em conseqüência de uma violação ou de uma lesão já verificada sobre o terreno do direito substancial e em função tipicamente repressiva da "fattispecie" do ilícito civil.

\subsection{Legitimidade e atualidade do interesse de agir}

O conceito de violação ou lesão do direito, colocado como fundamento da teoria da ação, constitui o ponto de referência essencial da noção de interesse de agir. C. Rapisarda ressalta que a questão da admissibilidade da tutela jurisdicional preventiva foi principalmente discutida em relação aos critérios de legitimidade e atualidade do interesse de agir. Como é de notar, o requisito da personalidade do interesse considerou, ao contrário, essencialmente o problema diverso da relação necessária entre titularidade do direito substancial e titularidade da ação, denunciando, de tal modo, um fenômeno de contaminação teórica entre interesse de agir e legitimatio ad causam. Pode-se dizer que o conceito de interesse legítimo de agir deriva, mediante a referência à noção de abuso do direito, da necessidade de colocar como fundamento da 
ação a denúncia de uma violação sofrida em conseqüência de um comportamento ilegítimo de uma parte, da qual pudesse derivar um dano incidente sobre a esfera jurídica da outra parte. Acentuava-se, por conseqüência, a concessão sancionatória da ação civil, uma vez que a efetiva subsistência do dano constrastava inevitavelmente com os requisitos de admissibilidade de uma tutela preventiva.

$\mathrm{Na}$ discussão em torno do requisito da atualidade do interesse, a opinião dominante sustentava que a efetiva subsistência do interesse de agir fosse de valorar, não só em relação à expressa denúncia de uma fattispecie lesiva de uma parte, mas também na demanda judicial de uma violação já verificada substancialmente, devendo a ação encontrar fundamento em um interesse jurídico atual. A necessidade de uma violação atual, como condição de prosperidade da ação civil excluía, radicalmente, a admissibilidade de qualquer remédio jurisdicional de conteúdo preventivo.

\subsection{A Tutela preventiva como remédio típico}

C. Rapisarda sublinha que, ao lado da formulação dos critérios gerais de individuação do conceito de interesse de agir, manifestou-se, na elaboração teórica de tal conceito em parte da doutrina pré-chiovendiana, uma orientação aparentemente menos restritiva sob o ponto de vista da admissibilidade da tutela preventiva.

Por um lado, o requisito da violação do direito, ligado à legitimidade do interesse de agir, sofria uma primeira atenuação na matéria da ação declaratória. Tal forma de tutela contrapunha já, ao menos implicitamente, a violação do direito ao simples desconhecimento dele, como fundamento substancial da tutela, respectivamente, condenatória e de verificação (accertamento). Mais especificamente, eliminava-se a violação ou lesão do direito das condições de prosperidade da ação de verificação.

Por outro lado, e passando do campo da tutela final ao da tutela propriamente cautelar, o princípio da atualidade do interesse de agir se considerava cumprido também no caso de possível violação futura, uma vez que, se observava, basta que haja perigo ou eminência grave de uma futura violação, pois o titular do direito possuía legítima faculdade de precaver-se, recorrendo ao juiz. A tal hipótese liga-se o exemplo da denúncia de obra nova.

$\mathrm{O}$ tendencial distanciamento do conceito de interesse de agir do requisito da violação (atual) do direito foi intensamente conexo, no plano argumentativo, com o elenco das espécies típicas de tutela preventiva final e cautelar. Não se tratou realmente de uma interpretação favorável à inserção no sistema de um princípio de prevenção do ilícito como remédio atípico, mas de uma referência à norma vigente que consentisse arraigar as condições da forma típica de tutela preventiva dentro da noção de interesse de agir.

\subsection{O recebimento da função de prevenção do ilícito na idéia de jurisdição}

O ano de 1903 assinala a afirmação do método sistemático na doutrina processualista italiana e, sobretudo, o abandono da concessão privatista do processo, que havia caracterizado o pensamento dos juristas do século XIX. A cultura processual do século XX inaugura-se 
com a afirmação, na sistematização teórica chiovendiana, da finalidade publicista do processo civil.

C. Rapisarda assinala que a abordagem publicista de Chiovenda e dos processualistas pós-chiovendianos favoreceram o recebimento da noção de tutela preventiva no conceito de jurisdição, também em conseqüência da afirmação do princípio da autonomia da ação do direito substancial.

A inclusão da finalidade de prevenção do ilícito na noção de jurisdição foi ditada, em larga medida, pela exigência de caráter sistemático que assinalou os limites da forma de tutela à qual a função jurisdicional preventiva poderia reconduzir-se. A teoria chiovendiana da jurisdição como função que objetivava a atuação da vontade concreta da lei resultava de fato extremamente conexa, no plano conceitual, com o princípio da autonomia da ação. $\mathrm{O}$ acolhimento da parte de Chiovenda da tese de Wach acerca da conexão teórica entre autonomia da ação civil e tutela de mera verificação (accertamento) a qual reconhecia a demonstração de total separação do direito de ação do direito material e de uma violação deste - foi, de fato, a região principal da propensão publicista da finalidade do processo e da jurisdição civil, visto que a separação entre ação e direito subjetivo substancial implicava necessariamente a superação da concessão privatista até então dominante. É possível concluir que a teoria chiovendiana do fim público da jurisdição civil postulava a acentuação do perfil preventivo da tutela própria enquanto representava a conseqüência teórica do reconhecimento de uma técnica particular de tutela, a de mera verificação atípica, na qual a intervenção jurisdicional precedia o cometimento do ilícito e que constituía o fundamento teórico do princípio da autonomia da ação. Segundo a concessão chiovendiana e segundo idêntica linha de pensamento de Calamandrei, a finalidade da prevenção do ilícito vinha oculta no conceito de jurisdição com exclusiva referência à tutela de mera verificação, como sede típica de exercício da função jurisdicional preventiva. Sobre essa base, de fato, Chiovenda manifestou seu próprio desacordo com a teoria de Redenti sobre o fim sancionatório da jurisdição civil. O dissenso partia da constatação que, em matéria de ação declarativa, não se realiza propriamente alguma atividade de aplicação da sanção, sendo em tal caso a intervenção jurisdicional direta à atuação do preceito primário, ao invés do secundário (i.e., sancionatório) da norma em contestação, em que não subsistiram, em similar hipótese, as condições úteis para uma intervenção autoritária sucessiva.

O tema da prevenção do ilícito constitui um momento essencial da obra de Carnelutti. Em seus escritos é, de fato, constante a formulação, sobre o plano da teoria geral, do conceito de medida sancionatória (não só repressiva, mas também) preventiva e a distinção entre finalidade repressiva e/ou preventiva do processo civil. Se se considera o momento final da evolução da doutrina carneluttiana, pode se observar que o sistema aparece fundado sobre a contraposição entre processo contencioso e processo voluntário, como instrumento de tutela direta, respectivamente, da repressão dos conflitos atuais e da prevenção dos conflitos potenciais de interesse. A teoria carneluttiana do processo e da jurisdição culminava, por isto, 
na afirmação da natureza substancialmente repressiva do processo contencioso, que se conectava, na hipótese de tutela condenatória, com a lide de pretensão insatisfeita, conseqüente à efetiva lesão do direito controverso e, na hipótese de tutela de mera verificação, com a lide de pretensão contestada, independente de uma concreta lesão do direito, mas referida a um fenômeno de transgressão da ordem jurídica. Isto que caracterizava a jurisdição contenciosa em sentido repressivo era a atualidade da lide, identificável também na ação meramente declarativa, ao passo que a função de prevenção vinha confinada no âmbito da jurisdição voluntária, diretamente como atividade de natureza estritamente jurisdicional, ao cumprimento de um "fazer" e à prevenção da lide (não atual, mas) potencial.

\subsection{A tutela de mera verificação como} remédio atípico de prevenção do ilícito

A acentuação do perfil preventivo da mera verificação deve o seu fundamento à construção chiovendiana de tal forma de tutela como remédio independente de um direito subjetivo de uma parte sobre a parte adversária e, diretamente, à conquista do bem, em si autônomo, da certeza jurídica em torno do direito ou relação jurídica contestada, ou comumente incerta.

O destaque da ação de mera verificação do direito substancial, mais que a função preventiva de tutela, constitui o momento central do pensamento chiovendiano sobre esse ponto em exame. Isto era, da outra parte, bem natural, porque a tratativa da matéria era finalizada, essencialmente, à demonstração do princípio da autonomia da ação, e fazia aparecer inadequada a distinção entre ação condenatória e de mera verificação fundada sobre a subsistência do requisito da violação atual do direito. Chiovenda negava, em substância, que a natureza preventiva da tutela valesse a distinguir a mera verificação da condenação e clarificava, assim, a necessidade de distingüir conceitualmente a mera verificação dos juízos preventivos. Emergia a concessão chiovendiana da mera verificação como forma de tutela independente de uma atividade jurídica do obrigado, liberada da existência de um direito substancial da parte autora e diretamente, ao invés, à satisfação de um (autônomo) interesse à certeza da relação.

Passando, todavia, do plano da construção dogmática ao da delimitação concreta do instituto, Chiovenda não pôde parar um pouco sobre a função preventiva da tutela de verificação. Isto é constatável tendo em consideração, primeiramente, a individuação dos pressupostos substanciais de tal forma de tutela e, em segundo, à precisão da sua finalidade no quadro complexo dos remédios jurisdicionais.

Sobre o primeiro item, pode-se dizer de fato que a espécie substancial posta por Chiovenda como fundamento da tutela de mera verificação colocava-se em uma fase antecedente da transgressão do preceito jurídico primário e, depois, à efetiva lesão do direito. A hipótese de simples contestação do direito, de incerteza acerca da existência de uma relação ou de um estado jurídico, de infundada afirmação de um direito a outro atribuído e, enfim, de incerteza ex re, independente, como no caso de cláusula contratual dúbia, do fato de alguém, prescindindo de uma violação substancial já realizada, caracteriza-se como fato 
promovido com respeito a um comportamento ilícito futuro.

Por outro lado, a negação de qualquer direta relação, sobre o plano conceitual, entre tutela de mera verificação e reintegração do direito subjetivo insatisfeito induz Chiovenda a restabelecer a conexão entre direito substancial e processo, imposição da necessária colocação da mera verificação entre as formas ordinárias de tutela jurisdicional, no único modo consentido de similar imposição dogmática, ou seja, mediante a referência à função preventiva desta particular técnica de tutela. "Prevenir os atos ilegítimos ao invés de ferir com peso de grave responsabilidade": nisso se fez consistir, em última análise, o fim prevalente da mera verificação judicial. Como clarificou Calamandrei (que expressa, nesta matéria, idêntica posição doutrinal), o provimento judicial surgiu como instrumento de tutela antecedente à transgressão do preceito jurídico primário e diretamente destinado a prevenir o perigo de futura transgressão mediante a eliminação da incerteza em torno da existência e dos limites da aplicação do preceito.

\subsection{Separação do interesse de agir em mera} verificação do requisito da violação do direito substancial

Segundo C. Rapisarda, a configuração chiovendiana de ação de mera verificação como instrumento geral de tutela derivou, em primeiro lugar, da afirmação do princípio pelo qual "o processo deve dar porquanto é possivel praticamente a quem tem um direito tudo aquilo e propriamente aquilo que tem direito de conseguir". A idéia chiovendiana de atipicidade da tutela teve aplicação, em matéria de ação declarativa, por meio do disposto no art. $36^{\circ}$ do CPC italiano, cuja formulação genérica parecia consentir a generalização da tutela de mera verificação e, conseqüentemente, a sua extensão a qualquer caso de incerteza jurídica considerada e de direitos subjetivos privados. Tal construção teórica foi possível de surgir menos, na matéria de ação declarativa, da conexão entre interesse de agir e violação do direito posto como fundamento da demanda, que tinha constituído o ponto de referência essencial da noção oitocentista de interesse de agir.

$O$ interesse de agir em mera verificação foi concebido por Chiovenda e pelos processualistas de sua escola como condição da ação independente da violação ou da lesão do direito material inferior. A incerteza objetiva, jurídica e atual, que fornecia o critério de individuação do interesse de agir em verificação, qualificava-se, de fato, como situação substancial precedente à verificação do evento lesivo, idônea a determinar a exigência de uma intervenção jurisdicional direta não tanto à reparação do dano já produzido, quanto à prevenção do dano que poderia no futuro derivar do prolongamento do estado de incerteza.

Todavia, a concessão do interesse de agir, proposta por Chiovenda e pelos chiovendianos, não implicou o recebimento no sistema processual de um poder geral de iniciativa judicial ante violationem, referível a cada forma de tutela jurisdicional. Do mesmo modo como o princípio chiovendiano de atipicidade da tutela vem especificamente referido à forma de tutela jurisdicional já contemplada na tradicional classificação das ações, a separação do interesse de agir da violação do direito, como pressuposto da 
tutela de verificação, acrescenta-se à corrente noção de interesse de agir como situação derivante da efetiva insatisfação do direito, que constituía o pressuposto de prosperidade da ação condenatória.

3.8 Observações críticas sobre a absorção da tutela de função preventiva final na mera verificação atípica

Para C. Rapisarda, a coincidência afirmada por Chiovenda e pelos processualistas póschiovendianos entre função de prevenção do ilícito, atuada mediante medidas de tutela final, e mera verificação atípica é fundada sobre três principais ordens de razão: em primeiro lugar, sobre uma exigência de construção sistemática; em segundo lugar, sobre uma particular visão da relação intercorrente entre direito substancial e processo. Enfim, sobre a inspiração ideológica, que caracterizou o pensamento processualista do início do século.

Sobre o primeiro perfil, pode-se dizer antes de tudo que a prioridade atribuída, no plano conceitual, à tutela de mera verificação foi, em larga medida, conseqüente à orientação geral sistemática dos processualistas da escola chiovendiana. Deste ponto de vista, passa em segundo plano o problema do contraste entre repressão e prevenção do ilícito, enquanto assume particular relevo a relação teórica subsistente entre ação de mera verificação e os princípios de autonomia da ação e, mais geralmente, entre a reconstrução chiovendiana da ação declarativa e a concessão publicista do processo. Esta última perspectiva encontra-se segura no pensamento de Chiovenda, enquanto a contraposição entre função jurisdicional repressiva e preventiva constitui um momento essencial, também ao fim da construção dogmática do sistema carneluttiano.

No período considerado, a discussão sobre tutela preventiva final se desenvolveu em torno da mera verificação judicial e reside nisso a potencialidade em sentido preventivo do sistema de remédios concessivos em via principal, movendo de uma concessão geral da tutela, cujos princípios inspiradores é necessário aprofundar.

Vem em consideração, neste propósito, o segundo problema antes assinalado, derivado da concessão das relações entre direito e processo, prevalente entre os processualistas considerados. Tendo em conta o quanto já se observou acerca da influência exercida, sobre a concessão oitocentista do direito de ação, da referência ao modelo substancial dos direitos reais típicos, parece possível acrescentar que similar posição foi comum também aos processualistas do primeiro decênio deste século, pela classificação que eles propuseram da técnica de tutela jurisdicional, sob o perfil do contraste entre repressão e prevenção do ilícito. De um lado, de fato, a resolução da função de prevenção do ilícito na tutela de mera verificação foi coerente com a prevalência acordada, no plano substancial, à categoria dos direitos reais, posto que, por meio do provimento judicial preventivo, consentia-se, em última análise, à teorização real como entidade jurídica independente dos singulares poderes jurídicos que formam seu conteúdo. Pode-se assim estar de acordo com Satta que o provimento judicial representou o meio específico de tutela dos direitos reais, enquanto a simples contestação de tais direitos - à diferença dos direitos de obrigações, em cuja a contestação da obrigação não constitui, por si, efetivo 
inadimplemento - integra os extremos de uma concreta espécie lesiva.

De outro lado, a concessão essencialmente repressiva da tutela condenatória e, correlativamente, a tipicidade da técnica de condenação preventiva implicavam um nexo de imediata funcionalidade entre essa forma de tutela e a categoria dos direitos reais, caracterizados, sob o perfil estrutural, do dado da tipicidade. Em outras palavras, a forma típica de condenação preventiva exauriu a exigência de tutela das situações substanciais consideradas emergenciais, sendo idônea a garantir a defesa do singular e de típicas espécies de ameaças lesivas.

Segundo C. Rapisarda, em linhas gerais, os princípios guias da nova escola sistemática, sobre a qual é formada a moderna doutrina processual (e, para C. Rapisarda, o sistema chiovendiando) foram inspirados pelo modelo institucional do Estado de direito de matriz liberal, revelando, de tal modo, uma continuidade ideológica com respeito à orientação de pensamento dos juristas oitocentistas.

A linha que divide, no plano conceitual, os chiovendianos dos processualistas do século passado deriva, em primeiro lugar, da adesão dos primeiros à doutrina publicista desenvolvida na Alemanha no final do século. $\mathrm{O}$ abandono da concessão privatista do processo e o acolhimento de uma visão publicista-autoritária das instituições processuais corresponde, em última análise à nova corrente, autoritária e filo-germânica, que caracterizou o liberalismo italiano do início deste século. Em outros termos, é possível afirmar que a operação conduzida pelos processualistas sistemáticos no plano da cultura jurídica teve encontro na "ilusão autoritária" dos moderados italianos, que favoreceram a evolução, em sentido estatal, das organizações institucionais liberais, como remédio temporal e necessário ao restabelecimento da ordem social turbada pelas manifestações dos primeiros movimentos coletivos de matriz socialista.

Desse modelo institucional derivou, em primeiro lugar, uma interpretação do binômio liberdade-autoridade tipicamente revolta a acentuar os valores de liberdade individual com respeito aos poderes de intervenção estatal, como emerge da concessão chiovendiana da ação em que atua, mediante a referência à categoria de direito potestativo, a compenetração entre os elementos a um tempo publicistas e privatistas do processo. A tendência encontra confirmação nos escritos de Calamandrei, em que a revalorização do direito subjetivo privado representava um freio à tendência estatizante, que se andava manifestando mais na Itália e na Alemanha.

A concessão da tutela preventiva foi condicionada de uma rigorosa delimitação dos poderes de ingerência estatal na esfera de livre determinação individual. Mais particularmente, a função repressiva da tutela condenatória derivou de uma delimitação tipicamente garantista dessa forma de tutela, como remédio em grau de incidir, pelo seu conteúdo, em sentido lato, prescritivo de comportamentos jurídicos, sobre a organização interna das relações jurídicas. De outro lado, a redução da tutela preventiva final na mera verificação foi ditada pela mesma orientação de pensamento, porque este particular instrumento de tutela garantia o predomínio da vontade individual na formação das relações interprivadas, como forma de mediação jurídica com a finalidade, 
em via exclusiva, a uma verificação de regularidade puramente formal da relação jurídica, já determinada, no conteúdo, pela autonomia privada.

3.9 A tendência sobre o recebimento no sistema de uma forma atípica de tutela preventiva cautelar

O quadro das posições expressas pelos processualistas da escola sistemática sobre o tema da tutela civil preventiva se completa com a análise da tendência emergente na definição dos limites de aplicabilidade da tutela preventiva cautelar. Sobre o recebimento pelo sistema de um "poder geral de cautela", os processualistas sistemáticos se pronunciaram em sentido nitidamente oposto à doutrina do século XIX pós-unitário. Assim como na sistematização da tutela declarativa prevalecia o dado da atipicidade, analogamente, em matéria de tutela cautelar, afirmava-se a exigência da forma atípica de cautela, em uma perspectiva de iure condendo.

Diversos fatores influenciaram tal orientação. De um lado, foram determinantes as sugestões provenientes da jurisprudência que, sucessivamente à codificação unitária, não cessaram de manifestar a propensão por um sistema de tutela cautelar mais amplo e elástico que o introduzido pelo código de 1865. Foi essencial, de outro lado, o modelo de alguns ordenamentos estrangeiros e, sobretudo, a introdução no sistema germânico da tutela cautelar atípica, na forma do einstweilige Verfügung.

Nos escritos chiovendianos, admite-se a existência, já in iure condito, de uma "figura geral" de "provimento provisório cautelar". Tal posição isolada, objeto de viva crítica de Calamandrei, foi principalmente determinada pelo reconhecimento teórico de uma autônoma "ação assecurativa", concebida como mera ação, como totalmente independente da efetiva subsistência da situação jurídica cautelanda. Também nesta matéria, a generalização da matéria encontrava seu fundamento na exigência de caráter sistemático, porque a autonomia da tutela cautelar do direito substancial cautelado constituía uma ulterior confirmação do princípio da autonomia da ação.

Calamandrei negou a possibilidade de considerar operante no sistema vigente um princípio de atipicidade da tutela cautelar, o que constituía uma direta conseqüência de sua concessão publicista da mesma tutela, como instrumento de garantia, não tanto dos direitos subjetivos individuais, mas da "eficácia da função jurisdicional”. Em tal perspectiva, um recurso mais generalizado à medida cautelar colocava-se em contradição, quanto menos em uma perspectiva de iure condito, como o liberalismo garantista próprio do pensamento de Calamandrei, podendo derivar o perigo de uma excessiva ingerência na esfera de liberdade individual.

\subsection{Conclusões segundo C. Rapisarda}

C. Rapisarda conclui que a exigência de superação do pensamento expressado sobre o tema da prevenção, no período considerado, se manifestou, sobretudo, no terreno da sistematização institucional da matéria. É profundamente alterado, de fato, o quadro de referência da técnica de prevenção do 
ilícito, com respeito à fase que limita a tutela processual preventiva à mera verificação atípica. Como se sublinha novamente, essa perspectiva encontra fundamento, de um lado, no individualismo garantista próprio do Estado liberal e, de outro lado, em um sistema privatista em que dominava a forma de propriedade estática e, mais geralmente, as situações substanciais reconduzíveis à categoria dos direitos reais.

Segundo C. Rapisarda, no contexto hodierno, em uma diversa disposição da relação entre indivíduo e Estado, corresponde a emergência de novos direitos que, em conseqüência da incidência exercida sobre a esfera jurídica privada dos modernos aparatos industriais e tecnológicos, requerem forma de tutela preventiva mais incisiva que a mera verificação idônea, como no caso da tutela inibitória, e prescrever a concreta modalidade de comportamento dos sujeitos privados.

\section{CONCLUSÃO}

A moderna sociedade de consumo, de massa, demanda por modificações no direito processual civil e na sua relação com o direito material. Esse panorama vem acompanhado de uma profunda revisão em todo o aparato jurídico legado pela Revolução Francesa que determinou o século passado e grande parte do século XX, pois, nesta virada de milênio, reconhece-se amplamente suas limitações.

Da idéia de instrumentalidade do processo deve-se evoluir para uma adequada tutela dos direitos. Um caso exemplar é a questão dos direitos fundamentais. A enunciação do reconhecimento dos direitos fundamentais nas constituições dos estados modernos é em número crescente. Tal fenômeno pode também ser visualizado no ordenamento internacional, mediante a aprovação de uma série de textos destinados a garantir os direitos do homem. A carência geralmente encontrada tanto no plano constitucional quanto no ordenamento internacional é precisamente a parte institucional e processual. Ao vasto consenso sobre as normas substanciais de direitos humanos nem sempre corresponde a predisposição das instituições em independente e objetivamente afirmarem a interpretação, a aplicação e a eventual sanção dessas normas de comportamento. ${ }^{7}$ A tutela inibitória pode suprir esta lacuna institucional e processual, como o meio adequado de tutela dos direitos fundamentais.

É possível visualizar um paralelismo de transformações entre o direito processual civil e o direito civil, notadamente entre a tutela inibitória e os movimentos de repersonalização, despatrimonialização e constitucionalização do direito civil. ${ }^{8}$ Deste modo, podemos concluir que as demandas pela revisão crítica da doutrina e do ordenamento jurídico clássico não ocorrem em áreas isoladas do pensamento jurídico, o que reforça a tendência de pensar e tornar o Direito mais eficaz em uma sociedade que se transforma cada vez mais rapidamente.

7 Sobre os direitos fundamentais e a convenção européia, pode-se consultar: BENAZZO, Antonella. Convenzione europea, misure d'emergenza $e$ garanzie giurisdizionali dei diritti dell'uomo. in Rivista Trimestrale di Diritto e Procedura Civile. Anno XLVII, n. 4. Milano, Dott. A. Giuffrè Editore, 1993. pp. 1141-1176.

8 Sobre as modernas tendências no Direito Civil, ver: Repensando fundamentos do direito civil brasileiro contemporâneo. Luiz Edson Fachin (coordenação). Rio de Janeiro, Renovar, 1998. 


\section{REFERENNCIAS}

BAUR, Fritz. Tutela jurídica mediante medidas cautelares. Porto Alegre: Sergio Antonio Fabris Editor, 1990.

BENAZZO, Antonella. Convenzione europea, misure d'emergenza e garanzie giurisdizionali dei diritti dell'uomo. in Rivista Trimestrale di Diritto e Procedura Civile. Anno XLVII, n. 4. Milano: Dott. A. Giuffrè Editore, 1993.

JACOB, Robert. Le jugement de Dieu et la formation de la fonction de juger dans l'histoire europeenne. in Archives du Philosophie du Droit. Tomo 39. Paris, Sirey, 1995.

MANCUSO, Fulvio. Per la storia della motivazione della sentenza nei secoli XVI-XVII
(Note in margine a studi recenti con il testo de una sentenza del 1299). in Rivista Trimestrale di Diritto e Procedura Civile. Anno XLIX, n. 1. Milano: Dott. A. Giuffrè Editore, 1995.

MARINONI, Luiz Guilherme. Efetividade do processo e tutela de urgência. Porto Alegre: Sergio Antonio Fabris Editor, 1994.

RAPISARDA, Cristina. Profili della tutela civile inibitoria. Padova: CEDAM, 1987.

Repensando fundamentos do direito civil brasileiro contemporâneo. Luiz Edson Fachin (coordenação). Rio de Janeiro: Renovar, 1998. 